\title{
BEHAVIOR OF ECCENTRICALLY LOADED SLENDER HIGH-STRENGTH CONCRETE COLUMNS
}

\author{
دراسة سلوق الأعمدة اللرفيعة من الخزساتة عالية المتاومة و المعرضة لاحمال فير محورية
}

\section{Ahmed M. Yousef}

\section{Lecturer, Structural Engineering Department, Faculty of Engineering, Mansoura University}

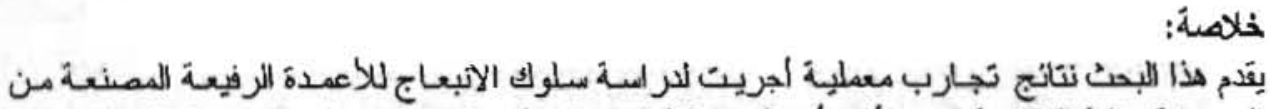

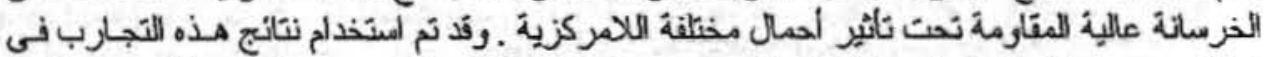

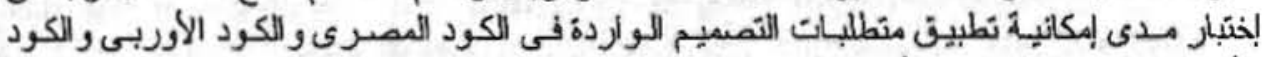

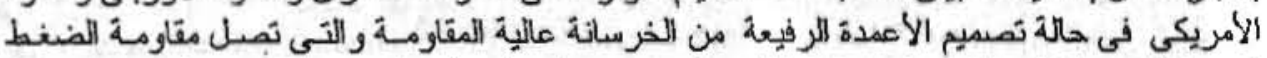

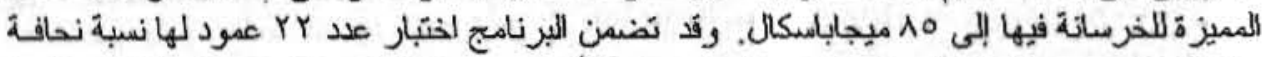

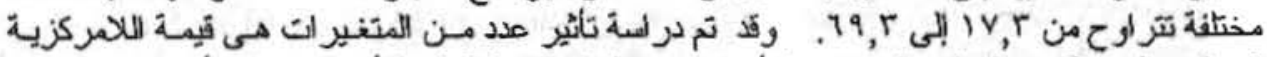

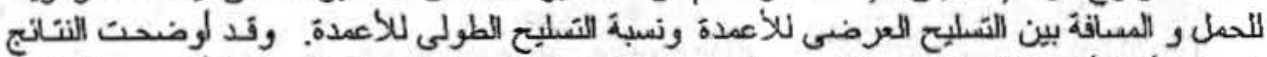

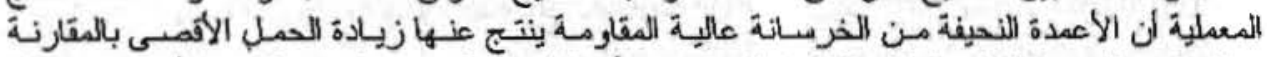

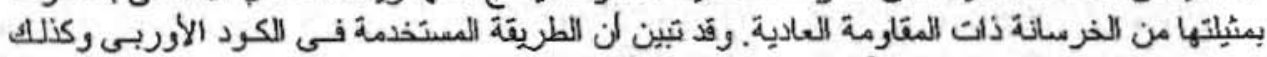

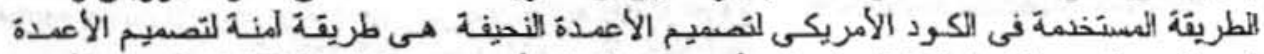

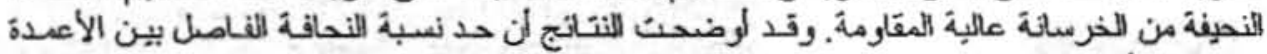

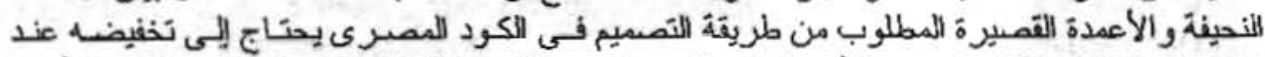

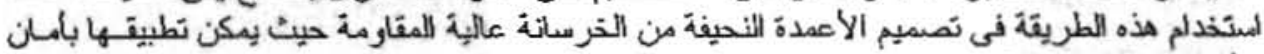

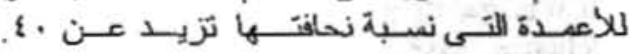

\section{ABSTRACT}

The buckling behavior of slender High-Strength Concrete (HSC) columns under axial load with different end eccentricities has been studied experimentally. The results of these tests have been used to examine the applicability of the design requirements of Norma!Strength Concrete (NSC) columns of the Eurocode 2 (EC-2), the Egyptian code (ECC-95) and $\mathrm{ACl}$ 318-99 building code, when applied to slender HSC columns with a characteristic comprëssive strength of $85 \mathrm{MPa}$. The program included tests of 22 columns with slenderness ratios $\lambda_{i}$ ranged between 17.3 and 69.3 . The main parameters examined in this study were the values of end eccentricity of the applied axial load $(e / t=0.3,0.45$ and 0.90$)$, the transverse reinforcement ratio $\left(\rho_{\nu}\right)$ and the longitudinal reinforcement ratio $\left(\rho_{l}\right)$. The results of this experimental work showed that, slender columns constructed with HSC increased the ultimate load of the tested columns in comparison with the same columns constructed with NSC. The Model Column method used by EC- 2 and also the Moment Magnifier method used by $\mathrm{ACl}$ 318-99 building code for the design of slender columns showed to be conservative for design of HSC slender columns. The sienderness ratio limit between short and long columns required by the ECC-95 need to be modified when applied for HSC columns. Based on the results of these tests, the second order effect should be taken into account for HSC columns when $\lambda_{1}>40\left(\lambda_{b}>12\right)$.

Keywords: High-Strength Concrete; Columns; Slenderness ratio; Eccentric Load; Codes.

Accepted July, 31, 2001 


\section{INTRODUCTION}

The advantages of High-Strength Concrete (HSC) include greater carrying capacity, reduced tead loads, longer spans and smaller member size. For this reason, the use of HSC in solumns of the high-rise buildings, among other applications, is increasing [1-3]. The reduction in column size results in significant economic benefits. However, this leads also to in increase in the slenderness ratio of columns. This has made it necessary to pay more attention to the stability of reinforced HSC columns.

There have been many experimental studies on Normal-Strength Concrete (NSC) short and long tied columns [4-9]. Experiments on HSC tied columns have been conducted by a umber of researchers in recent years. However, these tests have focused on HSC short solumns subjected to concentric and eccentric compression axial force [10-13]. More ecently, very limited test data have been reported on slender columns with end eccentricity $[14,15]$. Lloyd et al. [14] tested slender HSC columns with square and rectangular crossiections. Concrete strength of the tested columns ranged from $60-90 \mathrm{MPa}$ and the :lenderness ratio was 32 for square columns and 56 for rectangular columns. Mendis [15] iuggested a numerical method to conduct more accurate analysis of slender columns.

Although the design of reinforced concrete columns for buckling is by now a relatively well esearched subject, a variety of design methods are in use and the design requirements of the Igyptian Code (ECC-95) [16], Eurocode 2 (EC-2) [17] and ACI 318-99 building code [18] Jiffer markedly. In addition, the design equations given in theses codes for the design of ilender columns contain empirical relationships derived from tests using NSC.

$\mathrm{n}$ this paper, an experimental investigation to study the buckling behavior of slender HSC solumns subjected to end eccentricities is presented. The results of these tests were used o examine the applicability of the design requirements of NSC columns of the ECC-95, IC-2 and ACI 318-99 building code when applied to HSC slender columns.

\section{CODES PROVISIONS FOR DESIGN OF NON-SWAY (BRACED) ILENDER COLUMNS}

\section{sC-2}

tccording to this code, isolated columns in non-sway structures need not be checked for .econd order effects (including geometrical imperfections) if the slenderness ratio $\left(\lambda_{i}\right)$ is ess than or equal to the value of $\left(\lambda_{\text {crit }}\right)$ given by the following equation:

nd

$$
\lambda_{c r i t}=25\left(2-e_{o j} / e_{o 2}\right)
$$

$$
\lambda_{i}=\left(\beta . H_{\text {col }} / i\right)
$$

there $e_{01}$ and $e_{02}$ are the actual eccentricity of the applied axial loads at the ends of the olumn (called the first order eccentricity) and it is assumed that $\left|e_{o l}\right| \leq\left|e_{o 2}\right|, H_{c o l}$ is the usupported height of the column from top of floor to the bottom of the floor above, $i$ is the Idius of gyration (equal to 0.3 times the overali depth of rectangular columns) and $\beta$ is the ffective length factor which depends on the end conditions of the column and can be etermined by means of the Nomograms given in the code (for a braced frame $\beta \leq 1.0$ ). 
The second order effect due to buckling of the column can be calculated using the Model Column Method. This method can be applied for columns with $\lambda_{i}<140$ and the first order eccentricity $e \geq 0.1$. According to this method, the second order eccentricity $(\delta)$ of such a column may be calculated as follows:

$$
\delta=\frac{K_{I} H_{\mathrm{e}}^{2}}{10}(1 / \mathrm{r})
$$

and

$$
\begin{array}{ll}
K_{i}=\left(\lambda_{i} / 20-0.75\right) & \text { for } 15 \leq \lambda_{i} \leq 35 \\
K_{i}=1.0 & \text { for } \quad \lambda_{i}>35
\end{array}
$$

where $H_{e}$ is the effective length of the column $\left(H_{e}=\beta H_{c o l}\right)$ and the curvature $(t / r)$ can be calculated from the following equation:

$$
I / r=\frac{2 . K_{2} \cdot \varepsilon_{y d}}{0.9 d}
$$

where $\varepsilon_{y d}$ is the design yield strain of steel reinforcement $\left(\varepsilon_{y d}=f_{y d} / E_{s}\right)$ and $d$ is the effective depth of the cross-section in the expected direction of stability failure. The coefficient $K_{2}$ in Eq. 5 takes account of the decrease of the curvature with increasing the axial force and is defined by the following equation:

$$
\begin{aligned}
& K_{2}=\left(P_{u d}-P_{s d}\right) /\left(P_{u d}-P_{b}\right) \quad \leq 1.0 \\
& P_{u d}=0.85 f_{c}\left(A_{c}-A_{s}\right)+f_{y d} A_{s}
\end{aligned}
$$

Where $P_{u d}$ is the design ultimate capacity of the section subjected to axial load only, $P_{s d}$ is the actual design axial force and $P_{b a l}$ is the axial load which, when applied to a section, maximizes is ultimate moment capacity. For symmetrical reinforced rectangular sections, $P_{b}$ may be taken as $\left(0.4 f_{c}^{\circ} A_{c}\right)$, where $f_{c}$ is the design cylinder compressive strength of concrete, $f_{y t}$ is the design yield strength of longitudinal reinforcement, $A_{c}$ is the total area of the column cross-section and $A_{s}$ is the total area of the longitudinal reinforcement of the columin. It will be always conservative to assume that $K_{2}$ equal to 1.0 .

\section{ECC-95}

According to this code, a braced rectangular coimn is designed as short column if $\lambda_{b}=H_{e} b \leq 15$ or $\lambda_{i}=H_{e} / i \leq 50$. If the column slendemess ratio exceeds this limit, the column will buckle prior to reaching its limit state of material failure. The effect of buckling can be taken in design by an additional noment $\left(M_{\text {odd }}\right)$ induced by the deflection of the cohmn's buckled shape at the section being considered. 


$$
M_{\text {add }}=P \cdot \delta
$$

where $P$ is the applied ultimate axial load and $\delta$ is the induced deflection due to buckling which can be calculated from the following expression:

$$
\delta=\frac{\lambda_{b}^{2} \cdot b}{2000}
$$

where $b$ is the colutn dimension perpendicular to the axis of bending. According to this code, for rectangular cross section $\lambda_{b}$ should not be taken more than $30\left(\lambda_{i} \leq 100\right)$.

\section{ACI $318-99$}

In nonsway frames it shall be permitted to ignore slenderness effects for compression merabers that satisfy:

$$
\lambda_{i}=\left(\frac{k \cdot H_{\text {col }}}{i}\right) \leq 34-12\left(\frac{M_{i}}{M_{2}}\right)
$$

where $k$ is the effective length factor which depends on the end restrains of the column and can be determined by means of the Jackson and Moreland Alignment Charts given in the code (for a braced frame $k \leq 1.0$ ). The ratio of the moments $(M 1 / M 2$ ) at the two ends of the column in a braced frame will generally be taken between +0.5 and -0.5 .

For design of slender columns subjected to concentric or eccentric axial load, this code recommends the Moment Magnifier method (MM method). This method can be applied for columns with $\lambda_{i} \leq 100$. Let the ultimate column load and the larger end moment, from a first-order elastic frame analysis, be $P_{u}$ and $M_{u}=P_{u} . e$. It should be noted that, the design ultimate axial load according to the $\mathrm{ACl}$ code is given as follows:

$$
P_{u}=\varphi P_{n}
$$

where $\varphi$ is the strength reduction factor which, for tied columns, varies linearly as the nominal axial load capacity of the column cross section, $P_{n}$, varies from $P_{\alpha}$ to zero where $P_{a}$ is equal to the smaller of the balanced axial load $P_{b a l}$ or $\left(0.143 f_{c}^{\prime} A_{c}\right)$. If $P_{n}$ is greater than or equal to $P_{a}$, the factor $\varphi$ should be taken equal to 0.7, while if $P_{n}$ between $P_{a}$ and zero, $\varphi$ should be taken equal to $\left(0.9-0.2 P_{n} / P_{a}\right)$.

The load and the moment to be used in the design of the section are $P_{u}$ and $\left(\delta_{n s} M_{u}\right)$ where $\delta_{s}$ is the Moment Magnification Factor which is given by the following equation:

$$
\delta_{n s}=\frac{C_{m i}}{1-\left(P_{u} / 0.75 P_{c}\right)} \geq 1.0
$$

in which, $C_{n}$ is the equivalent moment factor and is given by the following expression: 


$$
C_{m}=0.6+0.4 \frac{M_{1}}{M_{2}} \quad \geq 0.4
$$

and the clastic buckling load $P_{c}$ is given as follows:

$$
P_{c}=\frac{\pi^{2} E I}{\left(k H_{c o l}\right)^{2}}
$$

where $E I$ is the flexural rigidity of column section. The value of $E I$ shall be taken equal to one of the values given by the following equations:

$$
\begin{aligned}
E I_{1} & =\frac{0.4 E_{c} I_{g}}{1+\beta_{d}} \\
E I_{2} & =\frac{0.2 E_{c} I_{g}+E_{s} I_{s e}}{1+\beta_{d}}
\end{aligned}
$$

The modulus of elasticity of concrete is given by the following equation:

$$
E_{c l}=4730 \sqrt{f_{6}^{\prime}}
$$

in which $I_{g}$ is the moment of inerlia of the gross concrete section about the centroidal axis ignoring the reinforcement, $E_{s}$ is the elastic modulus of steel, $I_{s e}$ is the moment of inertia of the reinforcement about the centroidal axis of the column cross-section and $\beta_{d}$ is the concrete creep factor. In this study, the creep of concrete was neglected. It should be noted that, ACI Committee 363 [3] recommended the use of the following equation for calculating the modulus of elasticity of HSC concrete:

$$
E_{c 2}=3320 \sqrt{f_{c}^{\prime}}+6900 \quad \text { for } 21<f_{i}^{*}<83 \mathrm{MPa}
$$

\section{DESCRIPTION OF COLUMN TEST UNITS}

\section{Test Specintens}

A tolal of twenty two short and long columns divided into six groups were constructed. The columns were square in cross-section ( $100 \mathrm{~mm} \times 100 \mathrm{~mm}$ ) and the thickness of the concrete cover measured from the bar center to the concrete surface was $20 \mathrm{~mm}$ as shown in Fig. 1 . The first group consists of three specimens constructed with NSC used for a comparison with the other HSC specimens. As shown in Table 1, the testing program included the following main studied parameters:

1. Three different slenderness ratios $\left(\lambda_{i}=H_{i} / i\right)$ were tested $\left(\lambda_{i}=17.3,52\right.$ and 69.3). The corresponding effective column heights $\left(H_{\text {col }}\right)$ were $500 \mathrm{~mm}, 1500 \mathrm{~mm}$ and 2000 mm, respectively. In addition, wo oher values of slenderness ratios $\left(\lambda_{i}=26\right.$ and 4).6) were tested in order to check the minimum values required by the studied codes. It should be roted that according to ECC-95, columns can be considered as siender if $\lambda_{i}>50$. $\Lambda$ ccording 
Table (1) : Details of test specimens.

\begin{tabular}{|c|c|c|c|c|c|c|c|c|c|c|}
\hline Group & Column & $\begin{array}{c}f_{c u} \\
(M P a)\end{array}$ & $\begin{array}{c}f_{c}^{\prime} \\
(M P a)\end{array}$ & $\begin{array}{l}H_{c o l} \\
(\mathrm{~mm})\end{array}$ & $\lambda_{i}$ & $\lambda_{b}$ & $\begin{array}{c}\text { Longit. } \\
\text { bars }\end{array}$ & $\begin{array}{c}\text { Transverse } \\
\text { Rft. Ratio } \\
\left(\rho_{v} \%\right)\end{array}$ & $\begin{array}{c}e \\
(m m)\end{array}$ & $e / t$ \\
\hline \multirow{3}{*}{1} & & $6 ?$ & 21.6 & 500 & 17.3 & 5.0 & $4 \phi 10$ & & 30 & 0.30 \\
\hline & & 26.2 & 1.6 & 1500 & 52.0 & 15.0 & $4 \phi 10$ & & 30 & 0.30 \\
\hline & $\mathrm{CN} 3$ & 26.2 & 21.6 & 2000 & 69.3 & 20.0 & $4 \phi 10$ & 13 & 30 & 0.30 \\
\hline \multirow{5}{*}{2} & $\mathrm{CH} 1$ & 85.1 & 75.8 & 50 & 17.3 & 5.0 & $4 \phi 10$ & 1.13 & 30 & 0.30 \\
\hline & & 1 & 75 & 750 & 26 & 7.5 & $4 \$ 10$ & & 30 & 0.30 \\
\hline & $\mathrm{CH} 3$ & 85.1 & 75.8 & 1200 & 41.6 & 12.0 & $4 \$ 10$ & & 30 & 0.30 \\
\hline & & 85.1 & 75.8 & 1500 & 52.0 & 15.0 & $4 \phi 10$ & & 30 & 0.30 \\
\hline & $\mathrm{CH}_{5}$ & 85.1 & 75.8 & 2000 & 69.3 & 20.0 & $4 \phi 10$ & & 30 & 0.30 \\
\hline \multirow{3}{*}{3} & & 85.1 & 75.8 & 500 & 17.3 & 5.0 & $4 \phi 10$ & 0.70 & 30 & 0.30 \\
\hline & & 85.1 & 75.8 & 1500 & 52.0 & 15.0 & $4 \phi 10$ & 0. & 30 & 0.30 \\
\hline & CH8 & 85.1 & 75.8 & 2000 & 69.3 & 20.0 & $4 \phi 10$ & 0.70 & 30 & 0.30 \\
\hline \multirow{3}{*}{4} & & 85.1 & 75.8 & 500 & 17.3 & 5.0 & $4 \phi 12$ & 0 & 30 & 0.30 \\
\hline & CH10 & 85.1 & 75.8 & 1500 & 52.0 & 15.0 & $4 \phi 12$ & .70 & 30 & 0.30 \\
\hline & CH11 & 85.1 & 75.8 & 2000 & 69.3 & 20.0 & $4 \phi 12$ & .70 & 30 & 0.30 \\
\hline \multirow{3}{*}{5} & 12 & 83.6 & 74.4 & 500 & 17.3 & 5.0 & $4 \phi 10$ & 1.1 & 45 & 0.45 \\
\hline & 13 & 83.6 & 74.4 & 1500 & 52.0 & 15.0 & $4 \phi 10$ & 1.13 & 45 & 0.45 \\
\hline & CH14 & 83.6 & 74.4 & 2000 & 69.3 & 20.0 & $4 \phi 10$ & 1.13 & 45 & 0.45 \\
\hline & CH15 & 83.6 & 74.4 & 500 & 17.3 & 5,0 & $4 \phi 10$ & 1.13 & 90 & 0.90 \\
\hline & CH16 & 83.6 & 74.4 & 750 & 26.0 & 7.5 & $4 \$ 10$ & 1.13 & 90 & 0.90 \\
\hline & CH17 & 83.6 & 74.4 & 1200 & 41.6 & 12.0 & $4 \phi 10$ & 1.13 & 90 & 0.90 \\
\hline & & 83.6 & 74.4 & 1500 & 52.0 & 15.0 & $4 \varphi 10$ & 1.13 & 90 & 0.90 \\
\hline & CH19 & 83.6 & 74.4 & 2000 & 69.3 & 20.0 & $4 \phi 10$ & 1.13 & 90 & 0.90 \\
\hline
\end{tabular}

to EC-2 the minimum values of $\lambda_{i}$ are given by Eq. (1) and Eq. (2), while according to the ACI 318-99, the minimum values of $\lambda_{i}$ are given by Eq. (10).

2. Three different conditions of end eccentricity $(e)$ were included in the test program (e=30,e $=45 \mathrm{~mm}$ and $e=90 \mathrm{~mm}$ ). The corresponding $e / t$ ratios were $0.3,0.45$ and 0.9 , as given in Table (1).

3. Two different longitudinal reinforcement ratios were used ( $4 \phi 10$ with $\rho_{l}=3.14 \%$ and $4 \phi 12$ with $\rho_{l}=4.52 \%$ ). These ratios are within the limits allowed by the codes inio consideration $\left(1.0 \% \leq \rho_{l} \leq 6.0 \%\right.$ according to ECC- 95$)$.

4. Two transverse reinforcement ratios $\left(\rho_{v}=1.13 \%\right.$ and $\left.0.70 \%\right)$ were tested. These were in the form of stirrups of bar diameter ( $\phi 6)$ but with two different spacing between stirrups ( $s=50 \mathrm{~mm}$ and $80 \mathrm{~mm}$, respectively). It should be noted that, for earthquake resistant design, the ECC-95 requires that $s$ should be the least of: 8 times the smaller longitudinal bar diameter $(8 \times 10 \mathrm{~mm}=80 \mathrm{~mm}) ; 24$ times the diameter of the stirrups $(24 \times 6 \mathrm{~mm}=144 \mathrm{~mm})$; half the length of the shorter column dimensions $(0.5 \times 100=50 \mathrm{~mm})$ or $150 \mathrm{~mm}$. 


\section{Concrete Properties}

In the HSC concrete mix design, ordinary portland cement was used in conjunction with 13 mm diameter gravel. The fine aggregate was oatural sand with a fineness modulus of 2.80 . The mix proportions by weight per $1.0 \mathrm{~m}^{3}$ was: Cement $475 \mathrm{~kg}$, Gravel $1180 \mathrm{~kg}$, Sand 580 $\mathrm{kg}$ and water $120 \mathrm{~kg}$. Light gray locally produced sitica fume with a specific gravity of 2.15 was used with 15 percent by weight of cement. A superplasticizer with 3 percent by weight of cement was added and enough mixing time was allowed to produce uniform mix of concrete without any segregation.

Standard specimens were prepared during casting of columns to obtain the mechanical properties of the used concrete. The concrete compressive strength $f_{\text {fur }}$ of the mix after 28 days based on an average of three cube specimens $(150 \times 150 \times 150 \mathrm{~mm}$ ) was $85 \mathrm{MPa}$. Additionally, the splitting cylinder tensile strength was equal to $4.82 \mathrm{MPa}$ and the flexural strength (based on beams $100 \times 100 \times 500 \mathrm{~mm}$ ) was equal to $8.91 \mathrm{MPa}$. Two cylinder (150 $300 \mathrm{~mm}$ ) were tested in uniaxial compression to determine the cylinderical compressive strength. The HSC tested specimens were constructed in 2 series included, in general, the columns tested with the same eccentricity. The cube compressive strength of the specimens $f_{c u}$ and the cylinder compressive strength $f_{c}^{\prime}$ after 28 days of casting are given in Table 1 .

The NSC mix proportions by weight per $1.0 \mathrm{~m}^{3}$ was: Cement $350 \mathrm{~kg}$, Gravel $1215 \mathrm{~kg}$, Sand $654 \mathrm{~kg}$ and water $147 \mathrm{~kg}$. The design concrete compressive strength $f_{c u}$ of the mix after 28 days was $25 \mathrm{MPa}$. Additionally, the splitting cylinder tensile strength was equal to $2.02 \mathrm{MPa}$ and the flexural strength was equal to $3.11 \mathrm{MPa}$.

\section{Reinforcement}

The main longitudinal reinforcement of each of the tested columns consists of four deformed high-grade bars with diameter $10 \mathrm{~mm}$ or $12 \mathrm{~mm}$ and the yield strength of these bars $f_{y}$ were equal to 397.0 and $382.0 \mathrm{MPa}$, respectively, while the maximum strength were 581.0 and $602.0 \mathrm{MPa}$, respectively. The recorded strain at the initiation of yield of these bars were 1890 and $1820 \mu \varepsilon$, respectively. The transverse reinforcement comprised $6 \mathrm{~mm}$ diameter mild steel bars with yield strength equal to $262.0 \mathrm{MPa}$ and maximum strength equal to $376.0 \mathrm{MPa}$.

\section{Test Setup and Instrumentation}

The columns were cast in forms made of wood with smooth hard varnish surfaces. The forms were removed after 48 hours from casting and columns were moistured continuously with water for 26 days. Then, the specimens were painted white, from one face only, to facilitate crack observation and tested after 28 days of casting.

The tests were conducted in the loading frame and the test setup is shown in Fig. 2. The boundary conditions at the ends were both hinged and the end eccentricities were of the same sign as shown in. Fig. 1. The lateral deflections at the midheight of the column were monitored by two dial gauges $0.01 \mathrm{~mm}$ accuracy. Electrical strain gauges of $120 \mathrm{ohm}$ resistance and $10 \mathrm{~mm}$ and $5 \mathrm{~mm}$ length. were bonded to the longitudinal reinforcement and the transverse reinforcement within the central $100 \mathrm{~mm}$ of the specimens. The concrete strains in the midheight of the test units were measured using mechanical strain gauge over the central $200 \mathrm{~mm}$ gauge length. The load was applied at increments of 0.5 or 1.0 ton up to failure and afier each load increment the cracks are traced and marked according to their priority of occurrence. 


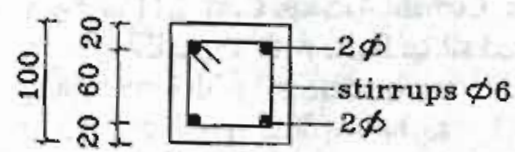

$$
100 \mathrm{~mm}
$$

SECTIOIN A-A
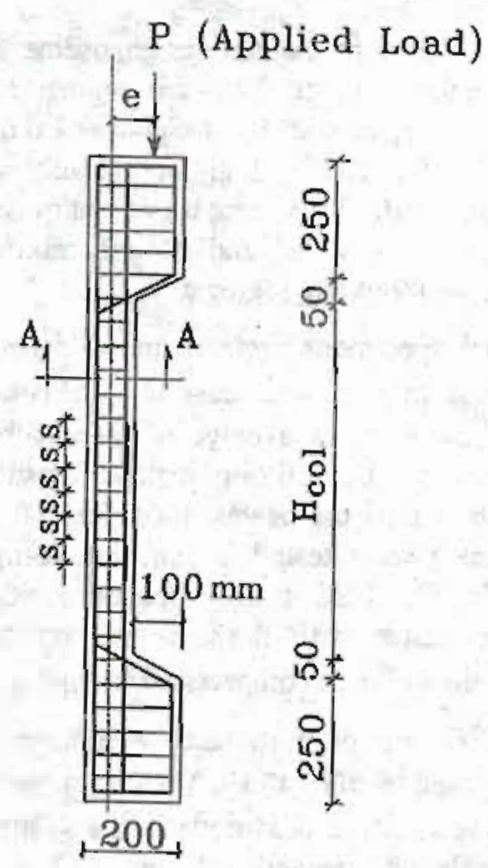

Fig. (1): Details of Column Specimens.

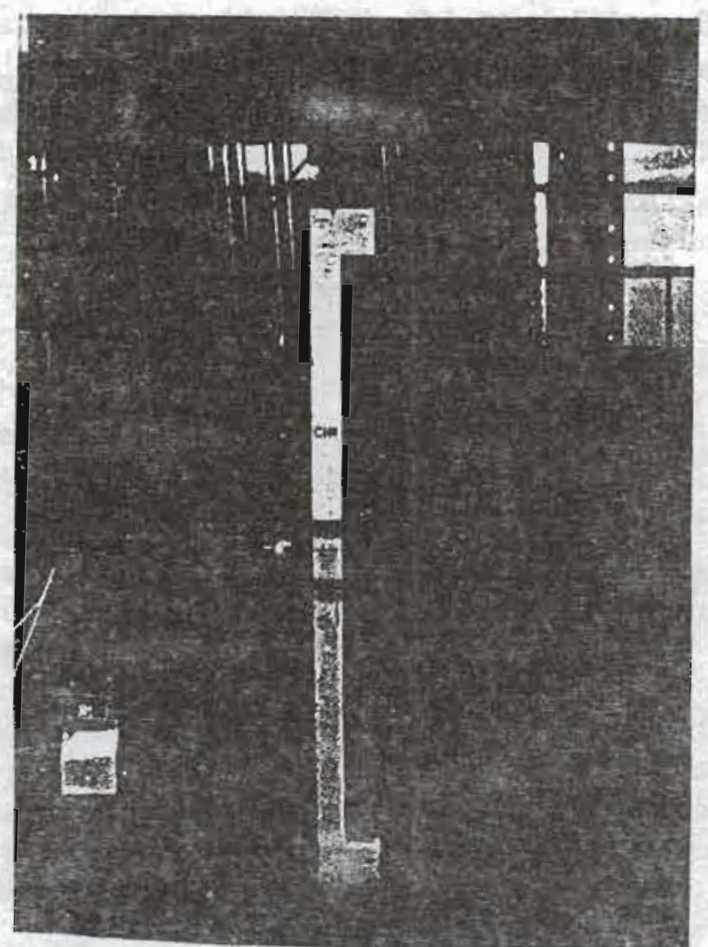

Fig. (2): Test setup. 


\section{RESULTS AND DISCUSSIONS}

\section{General Behavior and Ultimate Loads}

The recorded ultimate loads $P_{\text {uexp }}$ and the corresponding lateral deflections at midheight of the tested columns $\delta_{\text {exp }}$ are given in Table 2. Specimens $\mathrm{CH} 7$ and $\mathrm{CH} 12$ failed at relatively small ultimate loads. Failure of these two specimens occurred at their ends by compression of the heads because of the imperfect compaction of the ends during casting. Therefore, these specimens were not considered in the investigation. From Table 2, upon comparing the experimental ultimate loads for the HSC and NSC columns, column CH1 (with $e=30 \mathrm{~mm}$, $\lambda_{i}=17.3$ and $\rho_{l}=3.14 \%$ ) had an increase by $118 \%$ over the column CN1 which has the sine properties, but column CIIS $\left(\lambda_{l}-69.3\right)$ had an inerense by only $14.0 \%$. This showed that the increase of the experimental ultimate load due to increasing the concrete strength is decreased with the increase in the slenderness ratio.

Generally, most of the tested columns failed at or near to the midheight. The failure mode of the columns depends mainly on the eccentricity of the applied axial load. The tested HSC columns with big eccentricity (group 5 with $e=45 \mathrm{~mm}$ and group 6 with $e=90 \mathrm{~mm}$ ) failed by yielding of the longitudinal bars in the tension side, followed by a shift of the neutral axis toward the compression side until crushing of the concrete in the compression side of the section. It should be noted that, for group 5 and 6 , the calculated balanced eccentricity $\left(e_{b a t}\right)$ using the ACI stress block was equal to $42.2 \mathrm{~mm}$. For specimens tested with small eccentricity $\left(e=30 \mathrm{~mm}\right.$ ), most of columns with $\lambda_{i}=17.3$ and 26.0 failed at the midheight by increasing the compression strain until crushing of the concrete in the compression zone before yielding of the steel. The concrete cover, first, spalled off in the compression side and at later stages, the spalling of the cover extended to the side faces of the column. Slender specimens tested with small eccentricity ( $e=30 \mathrm{~mm}, \lambda_{i}=52$ and 69.3 ) failed due to increasing the tensile steel strain at the midheight up to yielding of the longitudinal reinforcement before the compression strain reaching the crushing value. The failure mode for the NSC specimens (group 1) was approximately the same as that of the specimens of the HSC specimens (group 2). Photographs of the failure mode of some of the tested HSC specimens are shown in Fig. 3.

The type of failure of the tested specimens can be explained also from the readings of strain recorded in the longitudinal reinforcement during the tests as shown in Fig. 4. It can be seen from Fig. 4a that. for specimen CHI, the recorded compressive strain increased gradually with increasing the applied load up 10 crushing of the concrete in the compression zone at strair reading of about $4000 \mu \mathrm{E}$, while the tensile steel strains was far from yielding. For specimens $\mathrm{CH} 4$ and CHS with $\lambda_{1}=52$ and 69.3 , respectively, the compressive strains increased gradually but the tensile strains increased witl a higher rate than that of the short columns CH1. In this case, because of the additional moment due to buckling of columns, the yrelding of the longitudinal reinforcentent in the tension side reached at low levels of compressive strains. For specimens with big eccentricity (group 6 with $e=90 \mathrm{~mm}$ ), it can be seen from Fig. 4b that, yjelding of the longitudinal reinforcement occurted always sooner at low vaiues of compressive strains in the compression zone. For example, the compressive strain in specimen CHI7 was equal to $(-805 \mu \varepsilon)$ at yiclding of steel in the tension side at $+1890 \mu \mathrm{E}$. 


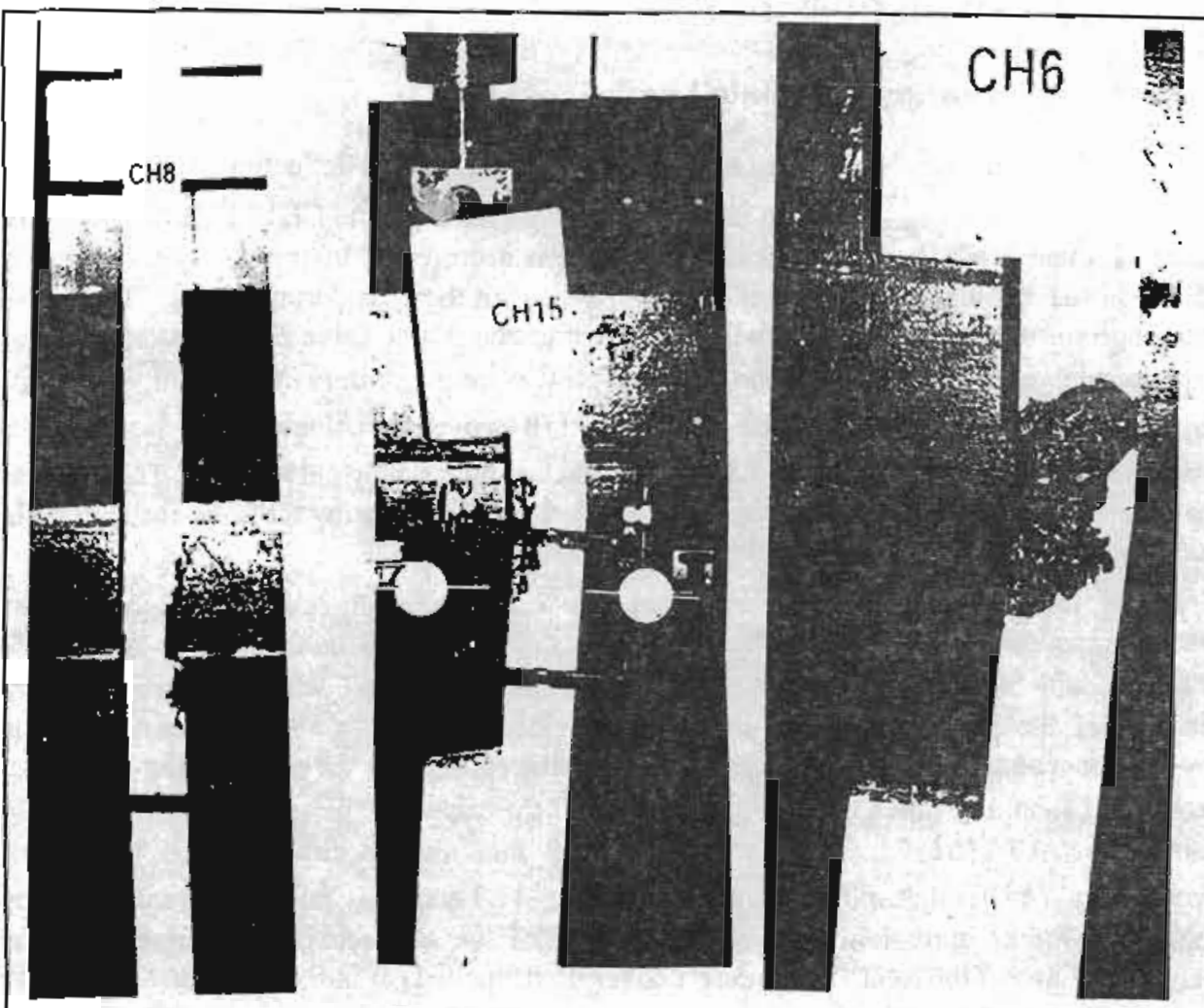

Fig. (3): Photographs of the failure mode of some of the tested columns.

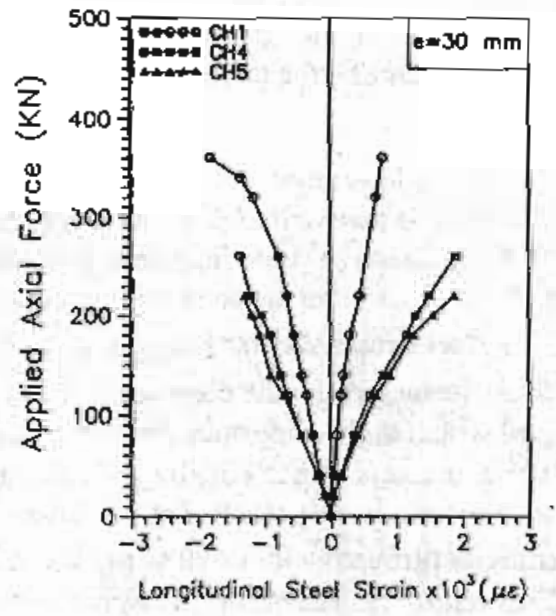

(a)

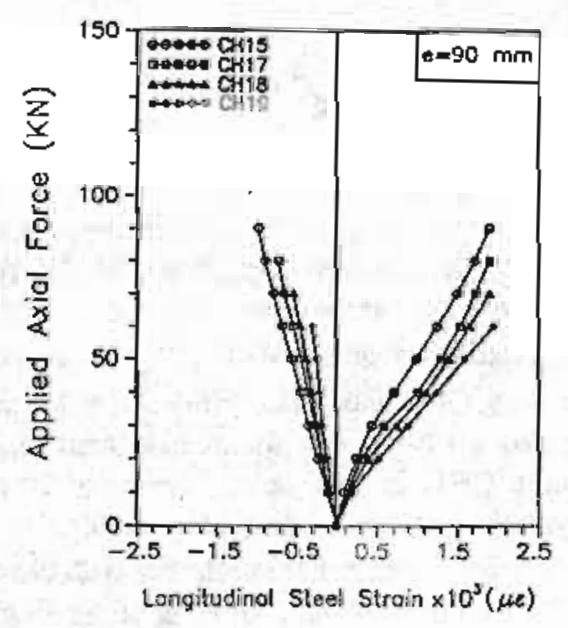

(b)

Fig. (4): Strains in the longitudinal bars of some of the tested columns. 


\section{Effect of Longitudinal Reinforcement Ratio}

The results of the tests of specimens with the same properties but with different longitudinal reinforcement ratios $\rho_{1}$ showed that the recorded ultimate load was dependent also on the value of $\rho_{i}$. Figure $S$ illustrates the effect of the longitudinal steel ratio on the ultimate load of the column. The calculated values of $P_{n}$ and the ratio $\left(P_{\text {uexp }} / P_{n}\right)$ for the tested specimens are reported in Table 2 , where $P_{n}$ is the nominal capacity of the column section for the case of $\lambda_{i}=0$ with the given eccentricity ( $e=30$ or 45 or $90 \mathrm{~mm}$ ). It should be noted that, the stress block of ACI $318-99$ code (taking $\varepsilon_{C u}=0.003$ ) was used in calculation of the values of $P_{n}$. The ratio $\left(P_{\text {uexp }} / P_{n}\right)$ for group $2\left(\rho_{l}=3.14 \%\right)$ and group $4\left(\rho_{l}=4.52 \%\right)$ show a small difference when the columns are relatively long, but the difference is increased with the decrease in slenderness ratio. Therefore, in this case, an increase of longitudinal stee ratio leads to a larger increment of $\left(P_{\text {uexp }} / P_{n}\right)$ value for a short HSC column than for a slender column.

\section{Effect of Transverse Reinforcement}

The test program included two transverse reinforcement ratios, which were in the form of the same stirrup bar diameter $(\phi 6)$ but with two different stirnps spacing ( $s=50 \mathrm{~mm}$ and 80 $\mathrm{mm})$. The results of the columns of group $3(s=80 \mathrm{~mm})$ and the similar columns of group 3 ( $s=50 \mathrm{~mm}$ ) showed that the recorded ultimate load of specimens of group 3 were less than that of group $2^{\circ}$ but with little differences. Specimens $\mathrm{CH} 6$ and $\mathrm{CH} 7$ of group 3 failed in a sudden explosive manner. At the time of failure, the cover concrete spalled and the longitudinal bars in the compression zone buckled. This type of failure occurred also for the specimens of group $4\left(s=80 \mathrm{~mm}\right.$ and $\left.\rho_{l}=4.52 \%\right)$. The provided transverse reinforcement of group 2 was sufficient to insure ductile failure for the specimens with small eccentricity $(e=30 \mathrm{~mm}$ ) and with different slenderness ratios. Buckling of the longitudinal bars in the compression zone of the tested specimens of group 3,5 and 6 was not observed. This showed that, the provided lateral reinforcement with spacing equal to half the length of the shorter column dimensions $(s=0.5 \times 100 \mathrm{~mm}=50 \mathrm{~mm})$ was adequate to prevent buckling of the longitudinal bars in the compression zone and to ensure ductile failure.

\section{Axial Force-Lateral Deflection Relation}

Figure 6 shows the relationship between the lateral deflections at midheight of some of the tested columns with the applied axial load. Generally, small lateral deflections were measured in the colunns with $\lambda_{f}=17.3$, while the columns with $\lambda_{i}=52$ and 69.3 were subject to large lateral deflections at the midheight of the column as shown in Fig.6a to $6 \mathrm{c}$. The value of the eccentricity of the applied axial load was the main factor affecting the lateral deflection of the specimens. It can be seen from Fig. 6d and $6 \mathrm{e}$, that the columns with smaller eccentricity (group 1-4) showed smaller values of lateral deflections compared witb that of the bigger eccentricity (group 5,6). The columns of the higher load eccentricity (group 6 with $e=90 \mathrm{~mm}$ ) showed greater deflections at ultimate load. At the end of the tests of this group (during the last $20 \mathrm{kN}$ ), it was observed that the specimens cracked and deformed significantly prior to failure. After reaching the maximum load, the columns continued to deform as an indication of a ductile behavior. It was observed also that, comparing with the NSC columns, the HSC columns showed a more sudden drop of load after the peak load. 
Table (2) : Summary of test results

\begin{tabular}{|c|c|c|c|c|c|c|}
\hline Grotp & Column & $\lambda_{i}$ & $\begin{array}{l}P_{\text {uexp }} \\
(k N)\end{array}$ & $\begin{array}{c}P_{n} \\
(k N)\end{array}$ & $\begin{array}{l}\delta_{\text {werp }} \\
(\mathrm{mm})\end{array}$ & $\left(P_{\text {uexp }} / P_{n}\right)$ \\
\hline \multirow{3}{*}{1} & $\mathrm{CN} 1$ & 16.7 & 188.5 & 154.3 & 4.55 & 1.22 \\
\hline & $\mathrm{CN} 2$ & 50.0 & 145.7 & 154.3 & 9.60 & 0.94 \\
\hline & $\mathrm{CN} 3$ & 66.7 & 117.1 & 154.3 & 13.20 & 0.76 \\
\hline \multirow{5}{*}{2} & CHI & 16.7 & 411.4 & 359.8 & 5.05 & 1.14 \\
\hline & $\mathrm{CH} 2$ & 25.0 & 368.6 & 359.8 & 5.90 & 1.02 \\
\hline & $\mathrm{CH} 3$ & 40.0 & 305.7 & 359.8 & 7.30 & 0.85 \\
\hline & $\mathrm{CH} 4$ & 50.0 & 288.6 & 359.8 & 9.40 & 0.80 \\
\hline & CH5 & 66.7 & 220.0 & 359.8 & 12.40 & 0.61 \\
\hline \multirow[t]{2}{*}{3} & Cllo & 16.7 & 100.0 & 359.8 & 5.30 & 1.11 \\
\hline & C118 & 66.7 & 211.4 & 359.8 & 11.90 & 0.59 \\
\hline \multirow{3}{*}{4} & CII9 & 16.7 & 420.0 & 391.5 & 5.20 & 1.07 \\
\hline & Cll10 & 50.0 & 305.7 & 391.5 & 10.20 & 0.78 \\
\hline & Cll11 & 66.7 & 242.9 & 391.5 & 13.10 & 0.62 \\
\hline \multirow[t]{2}{*}{5} & CH13 & 50.0 & 200.0 & 251.7 & 12.20 & 0.79 \\
\hline & CHI4 & 66.7 & 157.1 & 251.7 & 15.90 & 0.62 \\
\hline \multirow{5}{*}{6} & CHIS & 16.7 & 102.9 & 80.6 & 5.90 & 1.28 \\
\hline & CHIG & 25.0 & 97.1 & 80.6 & 7.10 & 1.20 \\
\hline & CH17 & 40.0 & 88.6 & 80.6 & 9.80 & 1.10 \\
\hline & CH18 & 50.0 & 80.0 & 80.6 & 13.40 & 0.99 \\
\hline & CHII & 66.7 & 71.4 & 80.6 & 18.60 & 0.89 \\
\hline
\end{tabular}

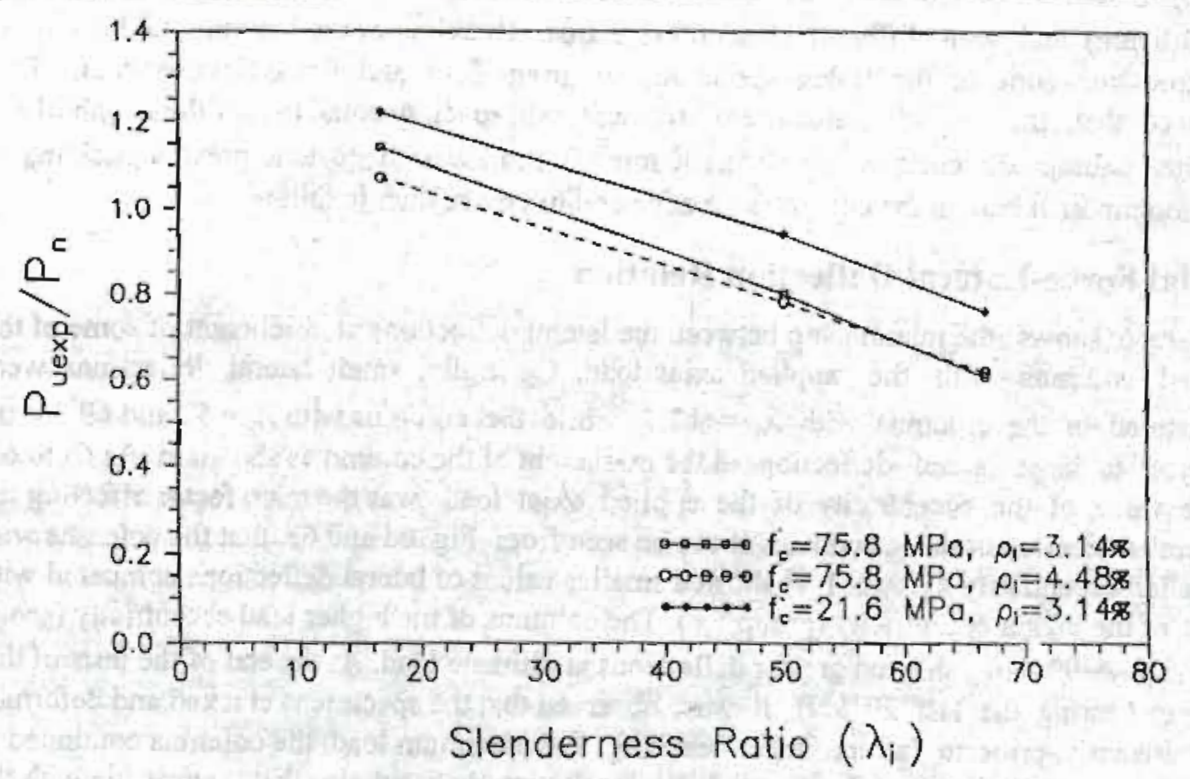

Fig. (5): Effect of longitudinal reinforcement ratio on the ultimate load. 


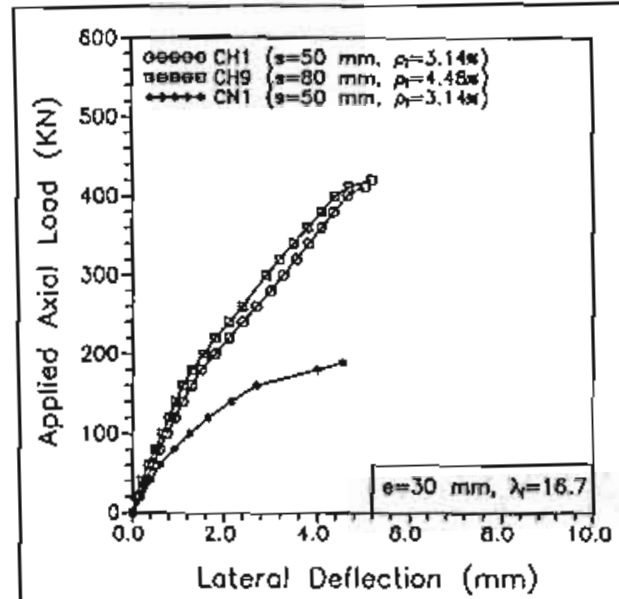

(a)

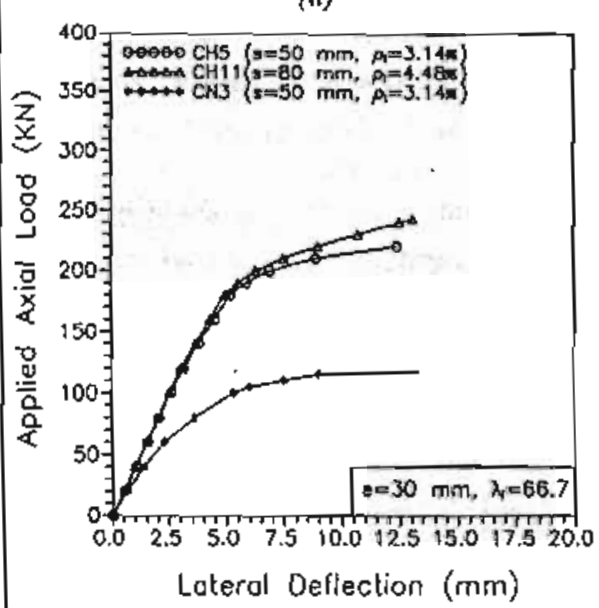

(c)

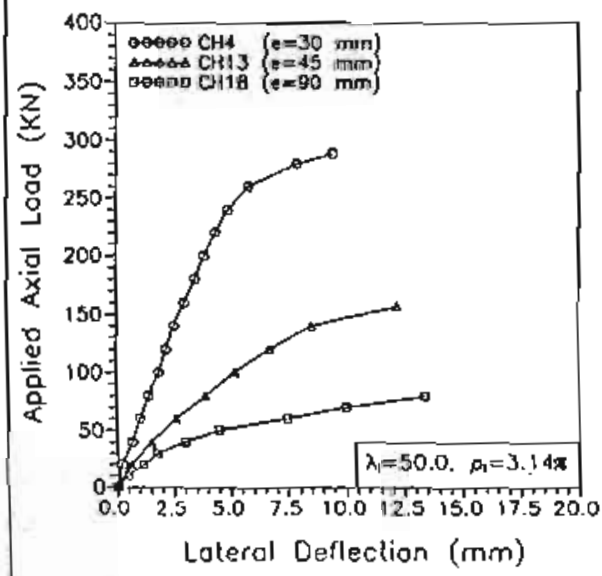

(d)

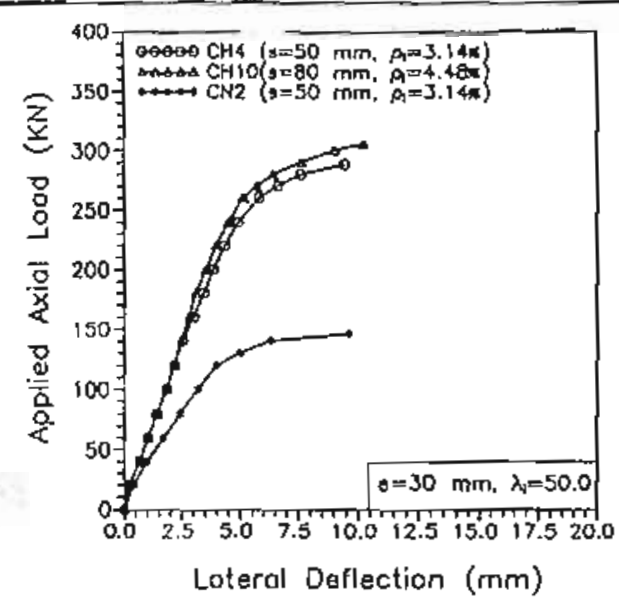

(b)

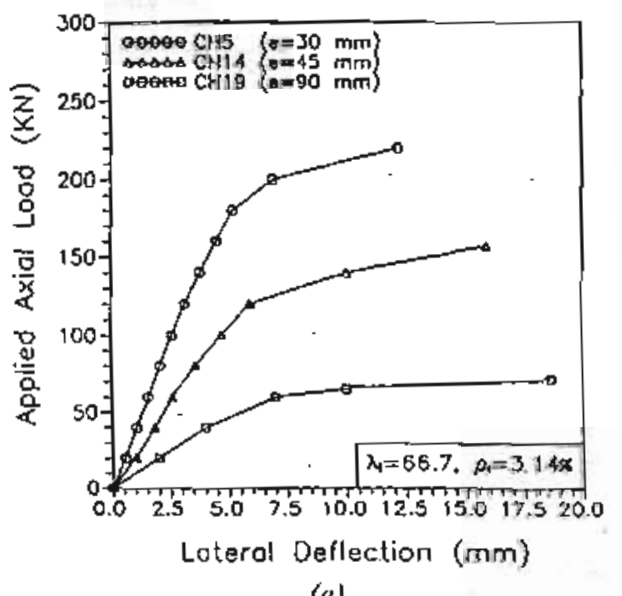

(e)

Fig. (6): Applied axial load-midheight lateral deflection relations of columns. 
The applied load-lateral deflection relationships for the specimens of group $3(\rho=0.7 \%)$ were approximately the same as that of the similar specimens of group $2\left(\rho_{v}=1.13 \%\right)$. This indicates that the transverse reinforcement ratio $\left(\rho_{v}\right)$ has negligible effect on the lateral deflection of the tested specimens. As shown in Table (2), the lateral deflections at ultimate loads ( $\delta_{\text {uexp }}$ ) for the columns of $\lambda_{i}=17.3$ show a little increase with the increase in concrete strength, however, for the columns of $\lambda_{i}=69.3$ they decreased. Increasing the longitudinal reicforcement ratio of the tested HSC columns with the same applied eccentricity (group 3 and group 5) increased by a very small percent the lateral deflections at ultimate loads for all the tested slenderness ratios as shown from Fig. 6a to $6 \mathrm{c}$.

\section{COMPARISON OF TEST RESULTS WITH CODES REQUTREMENRS}

The design methods for reinforced concrete slender columns of the ECC 95 and EC-2 were used to predict the ultimate load of the HSC and NSC columns of this study. The predicted values of ultimate lateral deflection at the midheight of the tested columns due to the second order effect $\left(\delta_{u d}\right)$ using the equations of ECC-95 and EC-2 are given in Table (3). In calculating $\delta_{u d}$ according to EC-2, the coefficient $K_{2}$ in Eq. 5 was taken equal to 1.0. It can be seen that, although the two codes use different methods for predicting the vitimate lateral deflection of the slender columns, the predicted values for the tested specimens with different applied eccentricity were approximately similar for columns with $\lambda_{i}$ greater than 40 . The recorded experimental ultimate lateral deflection $\left(\delta_{\text {uexp }}\right)$ showed to be, generally, less than that predicted by the 1wo codes for higher slenderness ratios while it was more than that predicted for lower slendemess ratio.

A comparison between the recorded experimental ultimate axial load $\left(P_{\text {uexp }}\right)$ with the preaicted values $\left(P_{u d}\right)$ using those two codes are given also in Table (3). The values of $P_{k d}$ was calculated from the equilibrium between the external forces (with the applied eccentricity $e=30$ or 45 or $90 \mathrm{~mm}$ in addition to $\delta_{u d}$ as calculated for each code) and the internal forces of the section. The capacity reduction factor $\varphi$ was adopted as unity in calculating $P_{u d}$ according to the two codes. It should be noted that, a rectangular stress block of maximum stress equal to $\left(0.85 f_{c}^{\prime}\right)$ and the ultimate concrete strain equal to 0.003 was used in calculation of the values of $P_{u d}$ for the two codes. The ECC-95 predictions were generally conservative for thirteen columns from a tolal of seventeen HSC columns with a mean (1.079) despite that the ECC-95 design equation is empirical and neglects the effect of many factors. The predictions of the model column method adopted in EC-2 were also conservative for fifteen columns from the tested seventeen HSC columns with a mean slightly more than that of the ECC-95 (1.112). For the two codes, the conservatism slightly decreased with increasing the slendemess ratio and considerably increased with increasing the applied eccentricity. For NSC columns the conservatism was more than that of the similar HSC columns. The tested slender columns of group $3\left(\lambda_{i}=52, \rho_{v}=0.70 \%\right.$ and $\left.\rho_{l}=3.14 \%\right)$ as well as that of group $4\left(\lambda_{i}=52\right.$ and $69.3, \rho_{v}=0.70 \%$ and $\left.\rho_{l}=4.52 \%\right)$ showed to be slightly unconservative for the two codes. This seems to be due to the reduction in $\rho_{v}$ from $1.13 \%$ to $0.70 \%$ (increase in stirnup spacing from $50 \mathrm{~mm}$ as required by the ECC-95 to $80 \mathrm{~mm}$ ) which resulted in a sudden brittle failure at relatively smaller ultimate load. 
it should be noted that, for the tested columns in Table (3), the EC-2 neglects the second order effects for the colurans with $\lambda_{i} \leq 25$. It is of great interest that ECC-95 considered the columns with $\lambda_{i}<50$ as short columns and the columns with $\lambda_{i}>50$ as long colurinns. For the ECC-95, the predicted ultimate force of the tested colurn $\mathrm{CH} 3$ with small eccentricity ( $e=30 \mathrm{~mm}$ and $\lambda_{t}=41.6$ ) was unsafe because of neglecting the second order effect, while according to the EC-2 the predicted ultimate force for the same column was conservative. This means that, in order to apply the present method of ECC-95 for design of slender HSC colurnns, the limits of the slenderness ratio for short columns need to be reduced. Based on the results of this experimental work, the ECC-95 method can be safely and conservatively applied to HSC columns with $\lambda_{i}$ more than $\lambda_{c r i}$ as given in EC-2 by Eq. 1 , but for simpliciry, $\lambda_{c r i}$ can be taken equal to 40 .

In order to compare the recorded experimental ultimate axial load with the predicted values using the Moment Magnifier method used by ACl 318-99 code, Figure 7 was used. This figure shows the ratio of $\left(P_{u} / P_{n}\right)$ calculated by the MM method with these obtained from the tests of some specimens. Four values of ultimate loads were calculated using Equations 15 to 18 . These values were referred to as $P_{\text {udACIII }}, P_{\text {udACII2 }}, P_{\text {udACI2l }}$ and $P_{u d A C / 22}$. These correspond to the calculated ultimate load using the modulus of elasticity $E_{C l}$ (Eq. 17$)$ and $E_{C 2}$ (Eq. 18), respectively. Each value of $E_{C}$ resulted in two values of the flexural rigidity ( $E I_{l}$ calculated using Eq. 15 and $E I_{2}$ calculated using Eq. 16). For example, $A C I 12$ means the values calculated using $E_{C I}$ and $E I_{2}$. It should be noted that, in calculating the flexural rigidity $E I$, the creep of concrete in the form of the concrete creep factor $\beta_{d}$ was ignored.

It can be seen from Fig. 7a, that $\left(P_{u} / P_{n}\right)$ values for the HSC columns $(e=30 \mathrm{~mm})$ are smaller than those for the NSC columns for all the tested slendeness ratio. The $\left(P_{u} / P_{n}\right)$ values for the HSC and NSC columns show a small difference in the case of $\lambda_{i}=17.3$, and a larger difference with increasing $\lambda_{i}$. A relatively small $\left(P_{u} / P_{n}\right)$ values for the tested slender HSC columns were recorded. This was due to the second-order effect, i.e., the ultimate load is reduced by the amplified bending moment caused by lateral deflection. For the HSC specimens tested under small eccentricity, the four methods of the $\mathrm{ACI}$ code were conservative. It should be noted that in calculating the moment magnification factor $\delta_{n s}$, the design ultimate axial load was calculated as given by Eq. 11. For the tested HSC columns with small eccentricity, the calculated values of $P_{u}$ exceeded the value of $\left(0.75 P_{c}\right)$ for the columns $\lambda_{i}=69.3$, and as a result, $\delta_{n s}$ was negative. This means that the stiffness is lower than expected and the ACI $318-99$ code requires that the column cross-section to be enlarged. For the same reason, the calculated values of $\delta_{\text {rts }}$ were more than $2.0^{\prime}$ for some columns with $\lambda_{i}<69.3$.

For the rested columns of big eccentricity (group 6), Fig. 7b showed that the ratio $\left(P_{t} / P_{n}\right)$ for all the specimens of this group were more than that predicted by the $\mathrm{ACI}$ methods. The level of conservation decre'sed with increasing the slenderness ratio. It should be noted that the calculated values of $\delta_{n s}$ for this group were more logical than that of group 3. It can be seen from Fig. 7a and $b$, that the predicted axial ultimate load of the tested HSC columns using the equation of $E_{c}$ proposed by $\mathrm{ACl}$ Conmittee 363 (Eq. 18) was more conservative than that predicted using $\mathrm{Eq}, 17$ used by the ACI 318-99. 
Table (3): Comparison of test results with the ECC-95 and EC-2 Predictions.

\begin{tabular}{|c|c|c|c|c|c|c|c|c|c|}
\hline \multirow{2}{*}{ Group } & \multirow{2}{*}{ Colum } & \multirow{2}{*}{$\begin{array}{l}\delta_{\text {uexp }} \\
(\mathrm{mm})\end{array}$} & \multirow{2}{*}{$\begin{array}{l}P_{\text {uexp }} \\
(k N)\end{array}$} & \multicolumn{2}{|c|}{ ECC-95 } & \multirow{2}{*}{$\frac{P_{u \exp }}{P_{d E C C-9 s}}$} & \multicolumn{2}{|c|}{$E C-2$} & \multirow{2}{*}{$\frac{P_{\text {uexp }}}{P_{d E C-2}}$} \\
\hline & & & & $\begin{array}{c}\delta_{u d} \\
(\mathrm{~mm})\end{array}$ & $\begin{array}{l}P_{u d} \\
(\mathrm{kN})\end{array}$ & & $\begin{array}{c}\delta_{u d} \\
(m m)\end{array}$ & $\begin{array}{l}P_{\text {ud }} \\
(\mathrm{kN})\end{array}$ & \\
\hline \multirow{3}{*}{1} & CN1 & 4.55 & 188.5 & 1.25 & 154.3 & 1.222 & 0.112 & 154.3 & 1.222 \\
\hline & $\mathrm{CN} 2$ & 9.60 & 145.7 & 11.25 & 125.6 & 1.160 & 11.81 & 123.1 & 1.184 \\
\hline & $\mathrm{CN} 3$ & 13.2 & 117.1 & 20.00 & 108.2 & 1.082 & 21.00 & 106.7 & 1.097 \\
\hline \multirow{5}{*}{2} & CHI & 5.05 & 411.4 & 1.25 & 359.8 & 1.143 & 0.112 & 359.8 & 1.143 \\
\hline & $\mathrm{CH} 2$ & 5,90 & 368.6 & 2.81 & 359.8 & 1.024 & 1.48 & 348.7 & 1.057 \\
\hline & $\mathrm{CH} 3$ & 7.30 & 305.7 & 7.20 & 359.8 & 0.850 & 7.56 & 302.0 & 1.012 \\
\hline & $\mathrm{CH} 4$ & 9.40 & 288.6 & 11.25 & 278.5 & 1.035 & 11.81 & 275.5 & 1.047 \\
\hline & CH5 & 12.40 & 220.0 & 20.00 & 219.5 & 1.002 & 21.00 & 213.3 & 1.031 \\
\hline \multirow[t]{2}{*}{3} & CH6 & 5.30 & 400.0 & 1.25 & 359.8 & 1.096 & 0.112 & 359.8 & 1.096 \\
\hline & CH8 & 11.9 & 211.4 & 11.25 & 219.5 & 0.963 & 11.81 & 213.3 & 0.991 \\
\hline \multirow{3}{*}{4} & CH9 & 5.20 & 420.0 & 1.25 & 391.5 & 1.073 & 0.107 & 391.5 & 1.073 \\
\hline & CHIO & 10.20 & 305.7 & 11.25 & 307.0 & 0.995 & 11.37 & 305.8 & 1.000 \\
\hline & CH11 & 13.10 & 242.9 & 20.00 & 258.4 & 0.940 & 20.22 & 256.8 & 0.946 \\
\hline \multirow[t]{2}{*}{5} & CH13 & 12.20 & 200.0 & 11.25 & 181.5 & 1.102 & 11.81 & 178.6 & 1.120 \\
\hline & CH14 & 15.90 & 157.1 & 20.00 & 142.3 & 1.104 & 21.00 & 137.2 & 1.145 \\
\hline \multirow{5}{*}{6} & CH15 & 5.90 & 102.9 & 1.25 & 80.6 & 1.277 & 0.112 & 80.6 & 1.277 \\
\hline & CH16 & 7.10 & 97.1 & 2.80 & 80.6 & 1.205 & 1.48 & 78.4 & 1.239 \\
\hline & CH17 & 9.80 & 88.6 & 7.20 & 80.6 & 1.099 & 7.56 & 70.4 & 1.258 \\
\hline & CH18 & 13.40 & 80.0 & 11.25 & 66.4 & 1.205 & 11.81 & 65.5 & 1.219 \\
\hline & CH19 & 18.60 & 71.4 & 20.00 & 58.0 & 1.231 & 21.00 & 57.1 & 1.250 \\
\hline
\end{tabular}

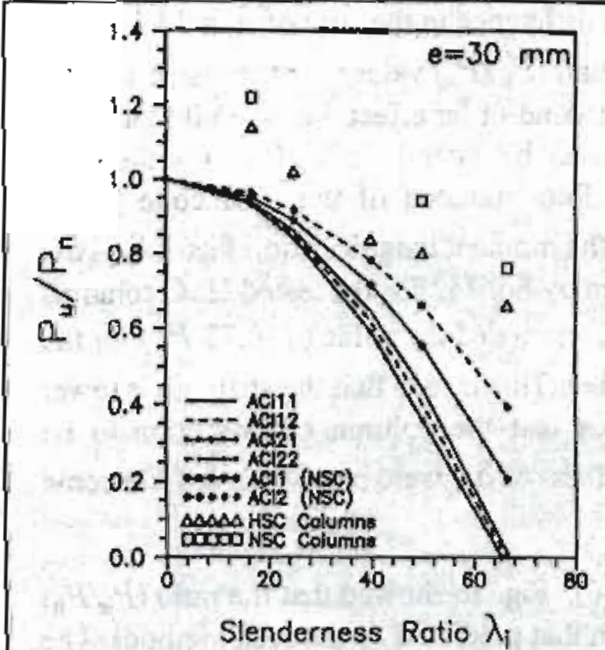

(a)

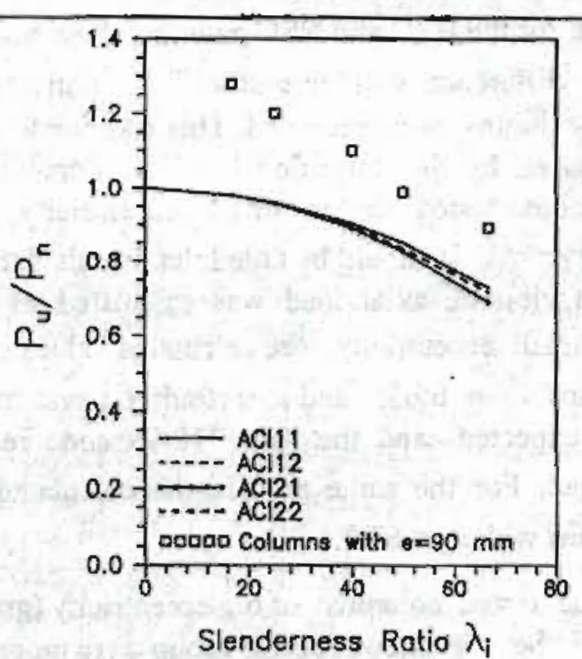

(b)

Fig. (7): Comparison of test results with the ACI $318-99$ predictions. 


\section{CONCLUSIONS}

Based on the results of this experimental investigation on the behavior of eccentrically loaded sleuder HSC columns with concrete cube compressive strength of about $85.0 \mathrm{MPa}$, the following can be concluded:

1. Slender columns constructed with HSC had increased ultimate load in comparison with the same columns constructed with NSC. Increasing the longitudinal reinforcement ratio slightly increased the ultimate load, while increasing the applied eccentricity increased the midheight lateral deflection and decreased the ultimate load.

2. The failure mode of the columns depends mainly on the magnitude of the eccentricity of the applied axial load. HSC columns tested with big eccentricity failed by typical flexural manner. HSC columns with small eccentricity $(e / t=0.3)$ and slenderness ratio $\lambda_{i}<25$ failed by crushing of the concrete before yielding of the tensiie reinforcement, while the columns with $\lambda_{i}>25$ failed due to increasing the tensile steel strain at the midheight up to yielding of the longitudinal reinforcement before the compression strain reached the crushing value.

3. The transverse reinforcement required by the ECC-95 for NSC columns was sufficient to easure ductile failure of the tested short and slender HSC columns subjected to small and big ecd eccentricity.

4. The Model Coluran method used by EC-2 for design of slender columns showed to be slightly conservative for design of HSC slender columns. The Moment Magnifier method used by $\mathrm{ACl}$ 318-99 building code was safe and conservative.

5. Although the ECC-95 equation for predicting the second order effect of slender columuns is empirical and neglects the effect of many factors, the results showed that this equation was conservative for the design of slender columns.

6. The slenderness ratio limit between the short and long columns required by the ECC-95 need to be reduced when applied for HSC columns. Based on the results of these tests, the second order effect should be taken into account for HSC columns with $\lambda_{i}>\lambda_{c r}$ used by the EC-2 and given by Eq. (1), but for simplicity, $\lambda_{c r i}$ can be taken mote than $40\left(\lambda_{b}>12\right)$.

\section{ACKNOWLEDGEMENT}

The author wishes to express his deep thanks for Prof. Dr. Salah El-Din El-Metwally, head of Structural Engineering Department, Faculty of Engineering, Tanta University and Assoc. Prof. Dr. Saad El-Din Mostafa for their kind help during preparing this work.

\section{REFERENCES}

1. ACI-ASCE Committee 441 (1997), "High-Sirength Concrete Columns: State of the Art," ACI Structural Joumal, V. 94, No. 3, May-June 1997, pp. 323-335.

2. Collins, M. P., Mitchel], D., and MacGregor, J. G. (1993), "Structural Design Considerations for High-Strength Concrete," Concrete International, V. 15, No. 5, May 1993, pp. $27-34$. 
3. ACI Committee 363 (1992), "State-of-the-Art Report on High-Strength Concrete", ACI 363R-92, American Concrete Institute, Detroit, 1992, 55 p.

4. Sheikh, S. A., and Uzumeri, S. M. (1980), "Strength and Ductility of Tied Concrete Columes," Journal of the Structural Division, ASCE, V. 106, No. ST5, May 1980, pp. 1079. 1102.

5. El-Gohary, H. (2001), "Strength and Deformations of Short Concrete Columns Under Eccentric Compression," Proceedings of the Ninth International Colloquium On Structural and Geotechnical Engineering, 10-12 April 2001, Faculty of Engineering, Ain Shams University, Paper No. RC17, Cairo, Egypt.

6. Ahmed, S. A., and El-Tuhami, A. A. (2000), "Effect of Steel Arrangement on the Behavior of RC Columns," Proceedings of the $8^{\text {th }}$ Arab Structural Engineering Conference, Structural Engineering Department, Faculty of Engineering, Cairo University, 21-23 October 2000, Cairo, Egypt, pp. 805-815.

7. Goyal, B. B. and Jackson, N. (1971), "Slender Concrete Columns Under Sustained Loads," Journal of the Structural Division, ASCE, V. 97, No. ST11, November 1971, pp. 2729-2750.

8. Johnston, B. G. (1983), "Column Buckling Theory: Historic Highlights," Journal of the Structural Engineering, ASCE, V. 109, No. 9, September 1983, pp. 2086-2096.

9. Rangan, V. B. (1990), "Strength of Reinforced Concrete Slender Columns," ACI Structural Journal, V. 87, No. 1, January-February 1990, pp. 32-38.

10. Foster, S. J., Liu, J. and Sheik, S. H. (1998), "Cover Spalling in HSC Columns Loaded in Concentric Compression," Joumal of the Structural Engineering, V., 124, No. 12, December 1998, pp. 1431-1437.

11. Razvi, S. R. and Saatcioglu, M. (1999), "Circular High-Strength Concrete Columns under Concentric Compression," ACl Structural Journal, V. 96, No. 5, September-October 1999, pp. 817-825.

12. Ibrahim, H. H., and MacGregor, J. G. (1996), "Tests of Eccentrically loaded HighStrength Concrete Columns," ACI Structural Journal, V. 93, No. 5, September-October 1996, pp. 585-594.

13. Abo Eleineen, A., Abd El-Faiad A. S., Zaher, A. H., and Montaser, W. M. (2000), "Behavior of High Performance Concrete Columns Under Eccentric Loading," Proceedings of the Second International Conference on Civil Engineering, Civil Engineering Department, Faculty of Engineering, Helwan University, Cairo, Egypt, 1-3 April 2000, pp. 805-815.

14. Lloyed, N. A., and Rangan, B. V. (1996), "Studies on High-Strength Concrete Columns Under Eccentric Compression," ACI Structural Journal, V. 93, No. 6, NovermberDecember 1996, pp. 631-638.

15. Mendis, P. A. (2000), " Behavior of Slender High-Strength concrete columns," ACI Structural Joumal, V. 97, No. 6, November-December 2000, pp. 895-901.

16. Ministry of Building and Infrastructures (1995), "Egyptian Code for Desigo and Construction of Reinforced Concrete Structures," Fourth Edition, Cairo, Egypt, 1998.

17. Commission of the European Communities (1990), "Eurocode No. 2: Design of Concrete Structures", Part 1: General Rules and Rules for Buildings, October, 1990.

18. ACI Committee 318 (1999), "Building Code Requirements for Reinforced Concrete and Commentary (ACl 318-95)," American Concrete Institute, Detroit, 1995. 